\title{
Recovery of systolic function in combination of non-compaction cardiomyopathy and tachycardiomyopathy after electrophysiological treatment
}

\author{
(i)Tatjana Zekić \\ Varljen*, \\ Damir Raljević, \\ (1) Vesna Pehar \\ Pejčinović, \\ (1) Viktor Peršić, \\ (1) Vladimir Peša, \\ OIngrid Buljanović
}

Clinic for rehabilitation, treatment and prevention of diseases of the heart and blood vessels,

Thalassotherapia Opatija, Croatia
RECEIVED:

February 28, 2019

ACCEPTED:

March 24, 2019

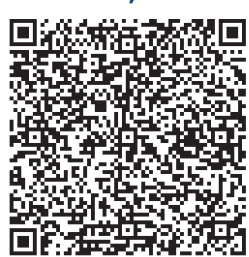

KEYWORDS: tachycardiomyopathy, non-compaction cardiomyopathy, paroxysmal supraventricular tachycardia, ablation.

CITATION: Cardiol Croat. 2019;14(3-4):99. | https://doi.org/10.15836/ccar2019.99

*ADDRESS FOR CORRESPONDENCE: Tatjana Zekić Varljen, Thalassotherapia Opatija, M. Tita 188/1, HR-51410 Opatija, Croatia. / E-mail: tatjana.zekic-varljen@tto.hr

ORCID: Tatjana Zekić Varljen, https://orcid.org/0000-0003-2905-8866 • Damir Raljević, https://orcid.org/0000-0001-9743-9201 Vesna Pehar Pejčinović, https://orcid.org/0000-0002-8921-7999 • Viktor Peršić, https://orcid.org/0000-0003-4473-5431 Vladimir Peša, https://orcid.org/0000-0002-6806-5674 • Ingrid Buljanović, https://orcid.org/0000-0003-0325-2847

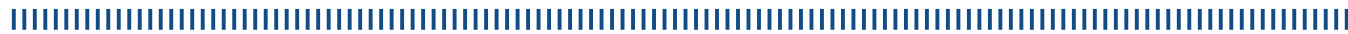

Background: Tachycardiomyopathy is an illness that is caused by accelerated and/or irregular cardiac rhythm, which result in myocardial damage and heart failure. There are no clear criteria for diagnosing this condition, but patient have weakness of the heart muscle with presence of some forms of heart rhythm. Non-compaction cardiomyopathy is disease which is result of a disturbance in the early phase of myocardial left ventricular development with deep recessions between trabeculae and abnormal trabeculation/hyperproliferation. This disease is associated with left ventricular failure, cardiac arrhythmias, embolic events, and sudden cardiac death., ${ }^{1,2}$

Case report: 39-year-old man with history of palpitation, ventricular arrhythmias, now complaining of tachycardia, palpitation and fatigue, was hospitalized in our Hospital for treatment of episode of paroxysmal supraventricular tachycardia which was converted in sinus rhythm with adenosine. Patient was not treated with any medical therapy before. Electrocardiography was shown episode of supraventricular tachycardia (PSVT) with short RP interval which was encouraged with ventricular extrasystole with retrograde conduction. We were suspected at atrioventricular circular tachycardia with retrograde conduction with aberrant beam. Echocardiography detected non-compaction cardiomyopathy with low left ventricular ejection fraction (LVEF), without element of coronary artery disease. Considering the earliest echocardiography findings with preserved LVEF, we conclude that with the existence of non-compaction cardiomyopathy, the tachycardiomyopathy was followed up to an additional reduced LVEF. With administered drug therapy followed by a significant reduction in the number of episodes of supraventicular tachycardia, the patient was discharged with the recommendation of taking verapamil, sacubitril/valsartan, eplerenone, dabigatran and we recommended ablation. After ablation, echocardiography findings that has been done, have shown global hypocontractility with preserved contractility posterolateral and better LVEF. After three months of ablation we made control magnetic resonance wich has shown discretely dimension reduction of left ventricle and still non-compaction cardiomyopathy with global hypokinesia but discreet recovery of LVEF and better feeling of patient.

Conclusions: The current clinical case have shown that the tachycardia weakened the global LVEF in this young man, who also have non-compaction cardiomyopathy, which was slightly improvement when we manage the fast tachycardia with drugs and ablation.

LITERATURE IIIIIIIIIIIIIIIIIIIIIIIIIIIIIIIIIIIIIIIIIIIIIIIIIIIIIIIIIIIIIIIIIIIIIIIIIIIIIIIIIIIIIIIIIIIIIIIIIIIIII

1. Jacquier A, Thuny F, Jop B, Giorgi R, Cohen F, Gaubert JY, et al. Measurement of trabeculated left ventricular mass using cardiac magnetic resonance imaging in the diagnosis of left ventricular non-compaction. Eur Heart J. 2010 May;31(9):1098-104. https://doi.org/10.1093/eurheartj/ehp595

2. Gopinathannair R, Etheridge SP, Marchlinski FE, Spinale FG, Lakkireddy D, Olshansky B. Arrhythmia-Induced Cardiomyopathies: Mechanisms, Recognition, and Management. J Am Coll Cardiol. 2015 0ct 13;66(15):1714-28. https://doi.org/10.1016/j.jacc.2015.08.038 